\title{
Adherence to Treatment in Patients with Rheumatoid Arthritis from Spain
}

This article was published in the following Dove Press journal:

Patient Preference and Adherence

\author{
Manuel Pombo-Suarez (iD) \\ Jose Ramon Maneiro \\ Fernandez $^{2}$ \\ Juan Jesus Gomez-Reino ${ }^{3}$ \\ 'Rheumatology Service, Complejo \\ Hospitalario Universitario, Santiago de \\ Compostela, Spain; ${ }^{2}$ Rheumatology \\ Service, Complejo Hospitalario \\ Universitario, Pontevedra, Spain; \\ ${ }^{3}$ Fundación Ramón Domínguez, \\ Complejo Hospitalario Universitario, \\ Santiago de Compostela, Spain
}

Objective: To evaluate adherence to treatment in a cohort of patients with rheumatoid arthritis in Spain and to identify potential predictors of adherence.

Methods: An observational, cross-sectional, multicenter study in outpatient clinics of Rheumatology Departments from 41 centers was conducted. A validated Spanish version of the compliance questionnaire in Rheumatology was used to measure adherence in a cohort of patients with rheumatoid arthritis, representative of the Spanish population. Univariate and multivariate analyses were performed to detect predictors of adherence.

Results: A total of 859 patients were recruited. An adherence rate of $79 \%$ was established. No differences were detected in adherence in patients receiving biologic disease-modifying antirheumatic drugs compared to conventional disease-modifying antirheumatic drugs, in patients receiving intravenous therapies compared to other routes of administration and in patients treated in specific day hospitals compared to polyvalent day hospitals. The number of drugs and cohabitation were independent predictors of adherence.

Conclusion: An inexpensive and useful method was used to measure adherence in Spanish population. The adherence rate in rheumatoid arthritis is still suboptimal. Simpler, more convenient dosing regimens may improve compliance. Increased knowledge of compliance in patients with rheumatoid arthritis and the identification of possible predictors of adherence will allow to develop effective intervention strategies.

Keywords: adherence, predictors, questionnaire, rheumatoid arthritis, Spain

\section{Introduction}

Rheumatoid arthritis (RA) is a chronic systemic autoimmune disease characterized by persistent synovitis, systemic inflammation and the presence of autoantibodies. Uncontrolled active RA causes joint damage, disability, decreased quality of life, and cardiovascular and other comorbidities. ${ }^{1}$ Current recommendations state that therapy with disease-modifying antirheumatic drugs (DMARDs) should be started as soon as the diagnosis of RA is confirmed. ${ }^{2}$

Adherence can be defined as the process by which patients take their medications as prescribed. This process includes initiation of the drug, implementation of the prescribed regimen and discontinuation of the drug. ${ }^{3}$ Lack of adherence contributes to an inadequate response or failure to treatment, worsening or disease relapse, and unnecessary treatment changes. ${ }^{4}$ It has been stated that compliance declines over time. ${ }^{5}$ This is important because a lack of adherence to pharmacologic therapy is a prevalent issue in the treatment of chronic diseases such as RA.

Adherence has not been widely examined for most rheumatic conditions. ${ }^{6}$ The ability of physicians to recognize nonadherence is poor, and interventions to
Correspondence: Manuel Pombo-Suarez Email mpombosuarez@gmail.com
Patient Preference and Adherence 202I:15 III-II7

| | |

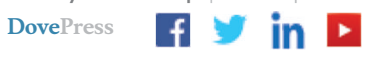

http://doi.org/10.2147/PPA.S291983 
improve adherence have had mixed results. ${ }^{7}$ Currently, a gold standard for the measurement of adherence is not available. $^{7,8}$ The use of patient questionnaires, an indirect method to measure adherence, is an inexpensive and useful method due to its simplicity. ${ }^{7}$ A compliance questionnaire in Rheumatology (CQR) was developed to measure compliance to treatment and to identify factors that contribute to suboptimal adherence in patients suffering from RA, polymyalgia rheumatica and gout. ${ }^{9}$ This 19 -item measure has been proven to be useful to predict compliance and identify barriers that interfere with it. ${ }^{9,10}$ Recently, the Korean and the Spanish versions of CQR, sCQR, for patients with RA have been validated. ${ }^{11,12}$ They showed high reliability with good test-retest results and a high predictive value suggesting that they could be used as screening instruments. In addition, the use of sCQR could also help to identify reasons for nonadherence. ${ }^{12}$

Increased knowledge of the impact of therapeutic adherence of patients with RA, and identification of possible predictors of adherence will allow to develop strategies to promote adherence. The main objective of this work was to describe the prevalence of treatment adherence in patients with RA in Spain using the sCQR. Secondary objectives were to detect possible differences in adherence in patients receiving biologic DMARDs (bDMARDs) compared to conventional DMARDS (cDMARDs) and/or glucocorticoids, in patients receiving intravenous therapies compared to other routes of administration and in patients treated in Rheumatology specific day hospitals versus polyvalent day hospitals. Another secondary objective was to identify potential predictors of adherence.

\section{Patients and Methods Study Design}

We performed an observational, cross-sectional, multicenter study in outpatient clinics of Rheumatology Departments from 41 centers in Spain.

Patients were invited to participate in the study during a routine visit to the rheumatology outpatient departments. In case of agreement, the SCQR was completed by the patient in the waiting room before seeing the rheumatologist and deposited in a box. In no case, the rheumatologist had access to the answers. If respondents did not understand any specific question or had trouble reading it, it could be read aloud to them verbatim, in any case, this would induce patients to respond in a certain way.
Demographic and disease data were collected during the visit. No diagnostic or therapeutic interventions other than those required by the routine practice were performed. Available data at the moment of the visit were obtained to ensure reflecting real-world practice with no interference.

\section{Study Population}

Adult patients that fulfilled the 1987 American College of Rheumatology (ACR) criteria for RA or RA diagnosis given by a rheumatologist, attending routine visits, were recruited on a consecutive basis. They had to be treated with glucocorticoids, cDMARDs (methotrexate, leflunomide, sulfasalazine, antimalarials) and/or bDMARDs (infliximab, adalimumab, etanercept, certolizumab, golimumab, tocilizumab, rituximab, abatacept) for at least 3 months and give their informed consent in order to participate in the study. Patients had to have the ability to complete the questionnaire or have someone who could help them in its completion.

\section{Sample Size and Center Selection}

To calculate sample size, results obtained in the preliminary study of the transcultural adaptation of sCQR were considered, where a $78 \%$ adherence to treatment was established. ${ }^{12}$ Estimating a similar proportion of therapeutic adherence and having in mind that the prevalence of RA in Spanish population is $0.5 \%{ }^{13}$ and Spanish population is $46,439,864$ inhabitants, for an alpha error of $5 \%$ and an accuracy of $3 \%$ it was estimated that the necessary sample would be 730 patients. Assuming a loss percentage of $15 \%$, a total population of 859 patients was determined to be necessary.

To achieve a representative sample, centers were selected across the Spanish geography according to population density and public health spending. Approximately 40 centers were estimated to be necessary. At least one region was randomly selected from each of the four groups, created according to stratification criteria, depending on population and health expenditure (supplementary Figure 1).

An effort was made to include as many regions and centers in the study. In each region, second- and third-level centers participated so that the sample was as representative as possible. The geographic variability of the recruited centers also contributed to guarantee this. The established minimum number of centers being selected in each group depended on the population of each of the groups. 


\section{Compliance Questionnaire in Rheumatology}

The compliance questionnaire in rheumatology $(\mathrm{CQR})$ is a 19item questionnaire that encompasses various aspects of adherence (Box 1). Spanish validated version was used in this study. Items indicating greater adherence (questions $1-3,5-7,10$ and 13-18) were scored from 3 to 0 (3, strongly agree; 2, agree; 1 , little agreement; 0 , completely disagree). Items indicating poorer adherence (questions 4, 8, 9, 11, 12 and 19) were scored from 3 to 0 ( 0 , strongly agree; 1 , agree; 2 , little agreement; 3 ,

Box I Compliance Questionnaire in Rheumatology

\section{Instructions to the Patient}

On the next pages you will find a number of statements made by patients with a rheumatic disease. Please indicate for each statement how far you agree, by placing a circle around the number that reflects your opinion best.

I. If the rheumatologist tells me to take medicines, I do so.

2. I take my anti-rheumatic* medicines because I then have fewer problems.

3. I definitely do not dare to miss my anti-rheumatic medications.

4. If I can help myself with alternative therapies, I prefer that to what my rheumatologist prescribes**.

5. My medicines are always stored in the same place, and that's why I do not forget them.

6. I take my medicines because I have complete confidence in my rheumatologist.

7. The most important reason to take my anti-rheumatic medicines is that I can still do what I want to do.

8. I do not like to take medicines. If I can do without them, I will ${ }^{* *}$.

9. When I am on vacation, it sometimes happens that I do not take my medicines**.

10. I take my anti-rheumatic drugs, for otherwise what's the point of consulting a rheumatologist?

II. I do not expect miracles from my anti-rheumatic medicines**.

12. If you cannot stand the medicines you might say: "throw it away, no matter what"***.

13. If I do not take my anti-rheumatic medicines regularly, the inflammation returns.

14. If I do not take my anti-rheumatic medicines, my body warns me.

15. My health goes above everything else and if I have to take medicines to keep well, I will.

16. I use a dose organizer for my medications.

17. What the doctor tells me, I hang on to.

I8. If I do not take my anti-rheumatic medicines, I have more complaints.

19. It happens every now and then, I go out for the weekend and then I do not take my medicines**.

The answers are scored on a 4-point Likert scale with anchors: I. do not agree at all; 2. do not agree; 3. agree; 4 . agree very much. *For gout patients, the word anti-rheumatic was changed to anti-gout. **These items were recoded to compute a total score. completely disagree). To adjust its weight, a coefficient was applied to each item, to generate a $Z$ score $\left(Z_{K}\right): Z_{K}=a+$ $\mathrm{W}_{1} \mathrm{X}_{1 \mathrm{~K}}+\mathrm{W}_{2} \mathrm{X}_{2 \mathrm{~K}}+\ldots+\mathrm{W}_{19} \mathrm{X}_{19 \mathrm{~K}}$, where $\mathrm{Z}_{\mathrm{K}}$ is the discriminant $\mathrm{Z}$ score for patient $\mathrm{K}$, a is a constant, $\mathrm{W}_{\mathrm{i}}$ is the discriminant weight for item $i$ and patient $K$. A cutoff point allowed classifying patients into those with satisfactory compliance or unsatisfactory compliance. ${ }^{12}$

\section{Data Collection}

The following data were collected: demographic data (age, sex, study level, civil status and cohabitation), data related to RA (disease duration, number of drugs used to treat RA, auxiliary drugs were not considered, eg folic acid or vitamin $\mathrm{D}$, glucocorticoids use and route of administration, cDMARD use and route of administration, bDMARD use and route of administration), hospital infrastructure (specific day hospital versus polyvalent).

\section{Ethics Statement}

The study was approved by Santiago-Lugo Ethics Committee (Registry Code: 2017/296 dated 29/05/2018). All the procedures were performed in accordance with the requirements for studies involving human participants and followed the principles stated in the Declaration of Helsinki. Both informed and written consent were sought from each participant using a consent form before enrollment in the study. Survey confidentiality and anonymity were assured to all enrolled participants.

\section{Statistical Analysis}

A descriptive analysis of all of the variables included in the study was performed. To identify if there were differences depending on the treatment received (bDMARDs versus cDMARDs), its route of administration or the area of origin, Chi2 was used. Likewise, in order to identify adherence predictive factors, a univariate and multivariate linear regression study adjusted for significant variables and for age and sex variables was performed. Values of statistical significance were considered at $p<0.05$. In the regression analysis, the categorical variables included were the number of medications the patient was taking, steroid use, use of cDMARDs, routes of administration of cDMARDs, use of bDMARDs, routes of administration of bDMARDs, health area, sex, level education, marital status and cohabitation. Continuous variables included in the regression analysis were the age and disease duration. For the statistical analysis, Stata version14.0 (Stata/MP14.0 for Windows; StataCorpLP, College Station, TX) was used. 


\section{Results}

A total of 859 patients contributed by 41 centers were selected and included in the study. All patients answered the questionnaire, 729 patients completed the 19 items and 130 skipped at least one of them. For analysis purposes, we considered patients who completed the 19 items. Baseline patient characteristics are shown in Table 1. A total of 418 patients $(48.7 \%)$ were being treated with bDMARDs and $682(79.3 \%)$ were receiving cDMARDs. Five hundred and sixty-five patients $(65.8 \%)$ were receiving more than one drug for the treatment of RA (glucocorticoids, cDMARDs and/or bDMARDs) at the time they filled the questionnaire.

An adherence rate of $79.01 \%$ was established. As for the secondary objectives, no differences were determined in adherence among patients related to the type of drugs

Table I Baseline Characteristics of Patients

\begin{tabular}{|c|c|}
\hline & $n=859$ \\
\hline Age (mean $\pm S D)$ & $60.2 \pm 12.6$ \\
\hline Female sex, n (\%) & $668(77.8)$ \\
\hline Duration of RA in year, median (IQR) & $8.7(3-9-15.7)$ \\
\hline $\begin{array}{l}\text { Level of education, } n(\%) n=743 \\
\text { - No studies } \\
\text { - Primary education } \\
\text { - Secondary education } \\
\text { - Superior education } \\
\text { - Other }\end{array}$ & $\begin{array}{l}51(6.8) \\
349(46.9) \\
209(28.1) \\
132(17.8) \\
2(0.3)\end{array}$ \\
\hline Civil status, $\mathrm{n}(\%) \mathrm{n}=754$ & \\
\hline $\begin{array}{l}\text { - Single } \\
\text { - Married } \\
\text { - Divorced } \\
\text { - Widow }\end{array}$ & $\begin{array}{l}86(11.4) \\
549(72.8) \\
53(7) \\
66(8.8)\end{array}$ \\
\hline Cohabitation, $n(\%) n=754$ & $658(87.3)$ \\
\hline $\begin{array}{l}\text { Number of drugs, } \mathrm{n}(\%) \\
\text { - } 1 \\
\text { - } 2 \\
\text { - } 3 \\
\text { - } 4 \\
\text { - } \geq 5\end{array}$ & $\begin{array}{l}294(34.2) \\
356(41.4) \\
140(16.3) \\
44(5.1) \\
25(2.9)\end{array}$ \\
\hline $\begin{array}{l}\text { Glucocorticoids, n (\%) } \\
\text { cDMARDs, n (\%) } \\
\text { bDMARDs n (\%) }\end{array}$ & $\begin{array}{l}367(57.3) \\
682(79.3) \\
418(48.7)\end{array}$ \\
\hline
\end{tabular}

Abbreviations: bDMARDS, biologic disease-modifying antirheumatic drugs; cDMARDs, conventional disease-modifying antirheumatic drugs; IQR, interquartile range; RA, rheumatoid arthritis; SD, standard deviation. they were receiving, bDMARDs versus cDMARDs $(\mathrm{p}=$ 0.1442), among patients receiving intravenous therapies versus other routes of administration $(p=0.7453)$ and among patients treated in specific day hospitals versus polyvalent day hospitals $(p=2.6815)$. The use of bDMARD combined with cDMARD also showed no difference in adherence compared to bDMARD monotherapy administration $(\mathrm{p}=0.314)$.

The univariate analysis detected the number of drugs and cohabitation as predictors of adherence to treatment (Table 2). When performing the multivariate analysis adjusted for sex and age, the same two variables remained as predictors of adherence, determining that both, number of drugs and cohabitation, are independent predictors of adherence.

To test for sensitivity, the same statistical analysis was performed including all of the 859 patients, without ruling out the patients who skipped questionnaire items, considering these patients as non-adherents. The univariate analysis detected the same variables, number of drugs and cohabitation, as predictors of adherence to treatment (sup plementary table 1). Civil status and age were also significant. Multivariate analysis adjusted for sex and age confirmed the number of drugs as an independent predictor of adherence.

Finally, ANOVA analysis was performed to test for sex and age influence on adherence and no statistical significance was detected.

\section{Discussion}

This study conducted in Spanish population shows that adherence to treatment occurred in $79 \%$ of patients with RA. Multivariate analysis, adjusted for age and sex, revealed that a number of drugs and cohabitation were independently associated with adherence in this population.

There are currently different methods to assess medication adherence. A lack of consensus exists when determining which is the best instrument. ${ }^{14}$ This study was conducted using a highly reliable and specific tool, being the only rheumatology-specific adherence measure, ${ }^{8,9}$ that has been recently validated for its use in Spanish RA population. ${ }^{12}$ It must also be stressed the special effort that was made when selecting centers to participate in the study, having into account geographical distribution and other variables, such as population density and public health expenditure for each region, in order to obtain 
Table 2 Association of Study Variables with Treatment Adherence

\begin{tabular}{|c|c|c|c|c|c|c|}
\hline Variables & $\begin{array}{l}\text { Univariate } \\
\text { Analysis }\end{array}$ & Coef. $(95 \% \mathrm{Cl})$ & $\begin{array}{l}\text { Multivariate } \\
\text { Analysis }\end{array}$ & Coef. $(95 \% \mathrm{Cl})$ & $\begin{array}{l}\text { Multivariate Analysis } \\
\text { Adjusted for Age and Sex }\end{array}$ & Coef. $(95 \% \mathrm{Cl})$ \\
\hline Duration of RA & 0.412 & $0.013(-0.02,0.04)$ & 0.839 & $0.004(-0.03,0.03)$ & - & - \\
\hline Number of drugs & 0.023 & $0.31(0.04,0.57)$ & 0.008 & $0.47(0.12,0.81)$ & 0.012 & $0.34(0.07,0.61)$ \\
\hline Glucocorticoids use & 0.282 & $0.33(-0.27,0.93)$ & 0.756 & $-0.11(-0.82,0.60)$ & - & - \\
\hline cDMARD use & 0.314 & $-0.37(-1.11,0.36)$ & 0.131 & $-0.72(-1.65,0.21)$ & - & - \\
\hline SC cDMARD vs oral & 0.275 & $-0.40(-1.13,0.32)$ & 0.544 & $-0.24(-0.10,0.53)$ & - & - \\
\hline bDMARD use & 0.750 & $0.11(-0.48,0.71)$ & 0.295 & $-0.42(-1.23,0.37)$ & - & - \\
\hline IV bDMARD vs SC & 0.597 & $0.22(-0.60,0.11)$ & 0.533 & $0.31(-0.66,1.28)$ & - & - \\
\hline Civil status & 0.062 & $-0.28(-0.58,0.01)$ & 0.571 & $-0.12(-0.55,0.31)$ & - & - \\
\hline Cohabitation & 0.046 & $-0.4 \mathrm{I}(-0.82,-0.01)$ & 0.348 & $-0.32(-0.10,0.34)$ & 0.023 & $-0.47(-0.88,-0.07)$ \\
\hline Education level & 0.387 & $-0.10(-0.31,0.12)$ & 0.765 & $0.04(-0.24,0.33)$ & - & - \\
\hline Sex & 0.357 & $0.34(-0.38,1.05)$ & 0.406 & $0.31(-0.42,1.04)$ & 0.359 & $0.33(-0.38,1.05)$ \\
\hline Age & 0.967 & $0.01(-0.02,0.02)$ & 0.744 & $0.004(-0.02,0.03)$ & 0.815 & $0.003(-0.02,0.03)$ \\
\hline $\begin{array}{l}\text { Specific day hospital } \\
\text { vs polyvalent }\end{array}$ & 0.299 & $0.20(-0.18,0.59)$ & 0.203 & $0.26(-0.14,0.67)$ & - & - \\
\hline
\end{tabular}

Abbreviations: bDMARDS, biologic disease-modifying antirheumatic drugs; cDMARDs, conventional disease-modifying antirheumatic drugs; Coef, regression coefficient; IV, intravenous; RA, rheumatoid arthritis; SC, subcutaneous.

a representative sample of Spain. Results obtained in this study can be extrapolated to the total Spanish population.

The adherence rate of $79 \%$ detected in this study is similar to rates observed in previous studies performed in Spanish population where an adherence of $79 \%$ was detected for patients being treated with oral antirheumatic drugs ${ }^{15}$ and $85 \%$ in the case of SC bDMARDs. ${ }^{16}$ Reported adherence rates in literature are highly variable, ranging from $30 \%$ to $80 \%{ }^{8}$ A systematic review of the literature estimated a $66 \%$ adherence to medication in patients with RA. ${ }^{17}$ Different definitions, methods, treatments and populations are behind this variability making it difficult to determine the magnitude of the problem. Optimal adherence depends on the type of drug and it remains to be determined in RA, if we understand optimal adherence as the relation between adherence level and disease flare. Independently of the definition of optimal adherence, we must be ambitious and try to ensure that patients follow treatment instructions rigorously. Nonetheless, adherence to treatment in RA patients is still suboptimal. ${ }^{8}$

The type of treatment did not determine the adherence rate in our study. No differences were detected in adherence among patients receiving bDMARDs versus cDMARDS and/or glucocorticoids. To our knowledge, this is the first study that studies the relationship between the type of therapy used to treat RA and adherence.

Our findings suggest that route of administration does not have an impact on adherence. This is in line with what has been shown in previous studies, where adherence and persistence rates appeared broadly similar for the different routes of drug administration in RA. ${ }^{18}$

The multivariate analyses determined that the number of drugs was an independent predictor of adherence. This fact is especially relevant, considering that treatment strategies in patients with RA rely heavily on the combined use of steroids, cDMARDs and bDMARDs. Contradictory results related to the impact of the number of medications on adherence have been reported. ${ }^{19-22}$ Regimen complexity (multiple medications, multiple doses, specific dietary or time requirements) has been related to poorer adherence in chronic diseases. ${ }^{23}$ Less frequent dosing has been related to better compliance. ${ }^{5,16}$ Simpler, more convenient dosing regimens resulted in better compliance. ${ }^{24}$ Since using complex regimens requires a good communication between doctor and patient, patients have to understand the consequences of not following the instructions correctly. Prescription needs to be a shared decision process, in order to achieve a consensus. Patient empowerment may have a positive effect on adherence; however, highly empowered patients might believe that they can make treatment decisions. Intelligent non-adherence is becoming a common term. Patients have to be properly informed.

The second independent predictor of adherence in this study was the cohabitation status. Living alone has been previously associated with poor adherence. ${ }^{25,26}$ Social 
support seems to be an important factor contributing to proper compliance. Family support has been related to an improvement in adherence to bDMARD in RA. ${ }^{27}$

Duration of disease, civil status, education level, sex and age were not identified as predictors of adherence. These findings are in line with previous reports in which no evidence for any association with adherence was determined. ${ }^{14}$

The study has several limitations. The study design, being cross-sectional, has to be considered. Adherence is not stable over time, having a dynamic nature. ${ }^{8}$ To address this issue, the inclusion of patients was not determined by disease duration so that patients in different stages of disease were included (Table 2). Patients had to be treated for at least 3 months but no upper limit on treatment duration was established. Disease activity was not measured and this variable may have an impact on adherence. Study population was not selected based on disease activity, participants reflected real-life RA population treated in routine clinical practice. Another disadvantage is the use of a self-reported questionnaire to test for adherence, even though it is a highly specific method with a highly predictive value, ${ }^{12}$ this method is relatively insensitive, since patients may claim to be adherent to avoid caregiver disapproval. ${ }^{8}$ Despite this, the use of indirect methods as the one used in this study is a more simple and feasible way to evaluate adherence and due to its highly predictive value, it can be used as a screening instrument. $^{12}$

Increased knowledge of the impact of therapeutic compliance on patients with RA, and the identification of possible predictors of adherence to treatment allows to develop strategies to favor adherence to treatments and avoid problems arising from lack thereof. In any case, prescription needs to be a shared decision process where clinicians and patients can discuss their concerns and expectations, in order to achieve a consensus that will favor adherence to treatment.

\section{Acknowledgments}

Alegre Sancho JJ, Almodovar Gonzalez R, Barbazan Alvarez C, Bernad Pineda M, Blanco Alonso R, Blanco Madrigal JM, Caliz Caliz R, Calvo Alen J, Calvo Catala J, Carrasco Cubero C, Castaño Sanchez M, Chamizo Carmona E, De Toro Santos FJ, Delgado Beltran C, Egües Dubuc A, Escudero Contreras A, Fernandez Nebro A, Gamero Ruiz F, Garcia Aparicio A, Hernandez Cruz B, Guerra Vazquez JL, Hernandez Miguel MV, Lopez Lasanta M, Marenco de la Fuente JL, Muñoz Fernandez Santiago, Navarro Blasco FJ, Nolla Sole JM, Ornilla Laraundogoitia E, Ortiz Garcia A, Pablos Alvarez JL, Perez Esteban S, Perez Garcia C, Roman Ivorra J, Romero
Yuste S, Rosello Pardo R, Salvador Alarcon G, Tornero Molina J, Urruticoechea Arana A, Vela Casasempere P.

\section{Funding}

This study was financed by Roche Farma S.A. Spain.

\section{Disclosure}

Dr Manuel Pombo-Suarez reports grants from Roche Farma S.A. Spain, during the conduct of the study. The authors report no other conflicts of interest in this work.

\section{References}

1. Scott DL, Wolfe FHT. Rheumatoid Arthritis. Lancet. 2010;376:1094-1108.

2. Smolen JS, Landewé R, Bijlsma J, et al. EULAR recommendations for the management of rheumatoid arthritis with synthetic and biological disease-modifying antirheumatic drugs: 2016 update. Ann Rheum Dis. 2017;76:960-977. doi:10.1136/annrheumdis-2016-210715

3. Vrijens B, De Geest S, Hughes DA, et al. A new taxonomy for describing and defining adherence to medications. $\mathrm{Br} J$ Clin Pharmacol. 2012;73:691-705. doi:10.1111/j.1365-2125.2012.04167.x

4. Shafrin J, Bognar K, Everson K, Brauer M, Lakdawalla DN, Forma FM. Does knowledge of patient non-compliance change prescribing behavior in the real world? A claims-based analysis of patients with serious mental illness. Clin Outcomes Res. 2018; Volume 10:573-585. doi:10.2147/CEOR.S175877

5. De Klerk E, Van der Heijde D, Landewé R, Van der Tempel H, Urquhart J, Van der Linden S. Patient compliance in rheumatoid arthritis, polymyalgia rheumatica, and gout. J Rheumatol. 2003.

6. Harrold LR, Andrade SE. Medication adherence of patients with selected rheumatic conditions: a systematic review of the literature. Semin Arthritis Rheum. 2009;38:396-402. doi:10.1016/j.semarthrit.2008.01.011

7. Osterberg L, Blaschke T. Drug therapy: adherence to medication. N Engl J Med. 2005;353:487-497. doi:10.1056/NEJMra050100

8. Van Den Bemt BJF, Zwikker HE, Van Den Ende CHM. Medication adherence in patients with rheumatoid arthritis: A critical appraisal of the existing literature. Expert Rev Clin Immunol. 2012;8:337-351. doi:10.1586/eci.12.23

9. De Klerk E, Van Der Heijde D, Van Der Tempel H, Van Der Linden S. Development of a questionnaire to investigate patient compliance with antirheumatic drug therapy. J Rheumatol. 1999.

10. De Klerk E, Van Der Heijde D, Landewé R, Van Der Tempel H, Van Der Linden S. The compliance-questionnaire-rheumatology compared with electronic medication event monitoring: a validation study. J Rheumatol. 2003.

11. Lee JY, Lee SY, Hahn HJ, Son IJ, Hahn SG, Lee EB. Cultural adaptation of a compliance questionnaire for patients with rheumatoid arthritis to a korean version. Korean J Intern Med. 2011;26:28. doi:10.3904/kjim.2011.26.1.28

12. Salgado E, Fernández JRM, Vilas AS, Gómez-Reino JJ. Spanish transcultural adaptation and validation of the English version of the compliance questionnaire in rheumatology. Rheumatol Int. 2018. doi:10.1007/s00296-018-3930-7

13. Carmona L. The prevalence of rheumatoid arthritis in the general population of Spain. Rheumatology. 2002;41:88-95. doi:10.1093/ rheumatology/41.1.88

14. Pasma A, Van't Spijker A, Hazes JMW, Busschbach JJV, Luime JJ. Factors associated with adherence to pharmaceutical treatment for rheumatoid arthritis patients: A systematic review. Semin Arthritis Rheum. 2013;43:18-28. doi:10.1016/j.semarthrit.2012.12.001 
15. Marras C, Monteagudo I, Salvador G, et al. Identification of patients at risk of non-adherence to oral antirheumatic drugs in rheumatoid arthritis using the Compliance Questionnaire in Rheumatology: an ARCO sub-study. Rheumatol Int. 2017;37:1195-1202. doi:10.1007/ s00296-017-3737-y

16. Calvo-Alén J, Monteagudo I, Salvador G, et al. Non-adherence to subcutaneous biological medication in patients with rheumatoid arthritis: A multicentre, non-interventional study. Clin Exp Rheumatol. 2017.

17. Scheiman-Elazary A, Duan L, Shourt C, et al. The rate of adherence to antiarthritis medications and associated factors among patients with rheumatoid arthritis: A systematic literature review and metaanalysis. J Rheumatol. 2016;43:512-523. doi:10.3899 jrheum.141371

18. Fautrel B, Balsa A, Van Riel P, et al. Influence of route of administration/drug formulation and other factors on adherence to treatment in rheumatoid arthritis (pain related) and dyslipidemia (non-pain related). Curr Med Res Opin. 2017;33:1231-1246. doi:10.1080/ 03007995.2017.1313209

19. Treharne GJ, Lyons AC, Kitas GD. Medication adherence in rheumatoid arthritis: effects of psychosocial factors. Psychol Heal Med. 2004;9:337-349. doi:10.1080/13548500410001721909

20. Van Den Bemt BJF, Van Den Hoogen FHJ, Benraad B, Hekster YA, Van Riel PLCM, Van Lankveld W. Adherence rates and associations with nonadherence in patients with rheumatoid arthritis using disease modifying antirheumatic drugs. J Rheumatol. 2009;36:2164-2170. doi:10.3899/jrheum.081204
21. Park DC, Hertzog C, Leventhal H, et al. Medication adherence in rheumatoid arthritis patients: older is wiser. $J$ Am Geriatr Soc. 1999;47:172-183. doi:10.1111/j.1532-5415.1999.tb04575.x

22. Kristensen LE, Saxne T, Nilsson JA, Geborek P. Impact of concomitant DMARD therapy on adherence to treatment with etanercept and infliximab in rheumatoid arthritis. Results from a six-year observational study in southern Sweden. Arthritis Res Ther. 2006;54:600-606. doi:10.1186/ar2084

23. Ingersoll KS, Cohen J. The impact of medication regimen factors on adherence to chronic treatment: A review of literature. J Behav Med. 2008;31:213-224. doi:10.1007/s10865-007-9147-y

24. Claxton AJ, Cramer J, Pierce C. A systematic review of the associations between dose regimens and medication compliance. Clin Ther. 2001;23:1296-1310. doi:10.1016/S0149-2918(01)80109-0

25. Lorish CD, Richards B, Brown S. Missed medication doses in rheumatic arthritis patients: intentional and unintentional reasons. Arthritis Care Res. 1989;2:3-9. doi:10.1002/anr.1790020103

26. De Cuyper E, De Gucht V, Maes S, Van Camp Y, De Clerck LS. Determinants of methotrexate adherence in rheumatoid arthritis patients. Clin Rheumatol. 2016;35:1335-1339. doi:10.1007/s10067016-3182-4

27. Morgan C, McBeth J, Cordingley L, et al. The influence of behavioural and psychological factors on medication adherence over time in rheumatoid arthritis patients: A study in the biologics era. Rheumatol. 2015. doi:10.1093/rheumatology/kev105
Patient Preference and Adherence

\section{Publish your work in this journal}

Patient Preference and Adherence is an international, peer-reviewed, open access journal that focusing on the growing importance of patient preference and adherence throughout the therapeutic continuum. Patient satisfaction, acceptability, quality of life, compliance, persistence and their role in developing new therapeutic modalities and compounds to optimize clinical outcomes for existing disease

\section{Dovepress}

states are major areas of interest for the journal. This journal has been accepted for indexing on PubMed Central. The manuscript management system is completely online and includes a very quick and fair peer-review system, which is all easy to use. Visit http:// www.dovepress.com/testimonials.php to read real quotes from published authors. 